\title{
Xenografting of testicular tissue pieces: 12 years of an in vivo spermatogenesis system
}

\author{
Lucía Arregui and Ina Dobrinski ${ }^{1}$ \\ Department of Biology, Faculty of Science, Universidad Autónoma de Madrid, C/Darwin 2, Madrid 28049, Spain and \\ ${ }^{1}$ Department of Comparative Biology and Experimental Medicine, Faculty of Veterinary Medicine, University of \\ Calgary, 3330 Hospital Drive NW, Calgary, Alberta T2N 4N1, Canada
}

Correspondence should be addressed to L Arregui; Email: lucia.arregui@gmail.es

\begin{abstract}
Spermatogenesis is a dynamic and complex process that involves endocrine and testicular factors. During xenotransplantation of testicular tissue fragments into immunodecifient mice, a functional communication between host brain and donor testis is established. This interaction allows for the progression of spermatogenesis and recovery of fertilisation-competent spermatozoa from a broad range of mammalian species. In the last few years, significant progress has been achieved in testis tissue xenografting that improves our knowledge about the factors determining the success of grafting. The goal of this review is to provide up to date information about the role of factors such as donor age, donor species, testis tissue preservation or type of recipient mouse on the efficiency of this technique. Applications are described and compared with other techniques with similar purposes. Recent work has demonstrated that testicular tissue xenografting is used as a model to study gonadotoxicity of drugs and to obtain sperm from valuable young males.
\end{abstract}

Reproduction (2014) 148 R71-R84

\section{Introduction}

Transplantation of testicular tissue was performed for the first time in 1767 by John Hunter. During the 19th century first Arnold Berthold and then others used testis grafting as a tool to probe the relationship between testes and secondary sexual characteristics and, later, androgens and spermatogenesis. These experiments were carried out by autotransplantation (grafts were introduced into the same animal) or homo- or allotransplantations (between genetically different individuals of the same species) in roosters, rats and mice (Setchell 1990). Also, the role of temperature and place of grafting was revealed as xenografts could be localised in the natural environment, the testis or the scrotum (known as homotopic or orthotopic grafting) or into a different part of the body; subcutaneous, intra-abdominal, etc. (heterotopic or ectopic grafting).

Around 1920 testis tissue hetero- or xenotransplantation (grafts are introduced into recipients of different species) was performed as an organotherapy by Serge Voronoff, John R Brinkley and others. Pieces of testes from young animals were transplanted into the old animals for the rejuvenation of the host, and soon this approach was applied to humans. Fragments of monkey and goat testes were xenografted into humans and surgeons claimed that it restored physical and intellectual abilities (Setchell 1990). However, Voronoff's statements were refuted and rejection of donor testicular tissue was demonstrated (Gunn \& Seddon 1930, Setchell 1990).

Later, the availability of immunodeficient mice, which do not reject donor cells and tissues, entailed an important contribution as it allowed for successful xenotransplantation. The first testicular xenografting as a tool to preserve the tissue was published in 1974 (Povlsen et al. 1974, Skakkebaek et al. 1974). They transplanted subcutaneously foetal human organs into nude mice and found, in the case of the testis, acceptance of tissue, preservation of histological structure and presence of gonocytes. Also, they reported xenotransplantation of rat testicular tissue into mice and found pachytene spermatocytes 40 days after grafting. But this fascinating finding was not pursued for almost 30 years until 2002 when the first complete testicular xenotransplantation into nude mice to rescue fertility from immature pigs and goats was published, showing that it allowed for the recovery of functional sperm (Honaramooz et al. 2002a). The success shown in this study sparked interest in this approach and since then, close to 100 studies have been published related to testis tissue xenografting with more than $45 \%$ of them in the last 5 years.

The purpose of this review is to summarise the stateof-the-art and breakthroughs in this field since 2002 while highlighting also the limitations and gaps in knowledge. Finally, the applications of this approach 
have been discussed and compared it with other techniques of in vitro spermatogenesis.

\section{An overview of testis tissue xenotransplantation}

Testicular tissue xenografting is performed by implanting pieces of testicular tissue into immunocompromised mice. It can be considered a specialised form of tissue culture in which the host mouse acts as a bioincubator for the grafted tissue. Xenografts can be placed into the testis, but most commonly are grafted under the skin of the mouse (Fig. 1). A functional circulatory connection is established between host and grafts. It was shown in rat testicular xenografts that the connection takes place by growing of capillaries from the grafts that connect, outside the graft, with newly formed larger vessels from the host mice (Schlatt et al. 2010a). This is different from the situation in human endometrium grafts, where it has been demonstrated that human vessel gradually regress and are replaced by mouse neovessels after xenografting (Eggermont et al. 2005). After revascularisation, a functional feedback loop is established between the pituitary of the host mouse and the endocrine cells in grafts and, over time (weeks or months), the xenografts grow and produce sperm (Fig. 1). At that time, testicular tissue can be harvested, and sperm isolated from xenografts, lacking maturation in the epididymis, are functional for fertilisation after ICSI. Spermatozoa obtained from goat xenografts were able to initiate the fertilisation process after injection into mouse oocytes
(Honaramooz et al. 2002a). Also, when xenogeneic rhesus monkey spermatozoa or cattle round spermatids were injected into homologous oocytes, embryonic development was confirmed by reaching the blascocyst stage (Kaproth et al. 2002, Honaramooz et al. 2004). Similarly, male and female pronuclear formation took place after injection of dog sperm into heterologous (sheep) oocytes (Shirazi et al. 2014). In addition, production of viable offspring that grew up normally and being fertile has been reported in rabbits and pigs after the embryos were transferred into recipient females (Shinohara et al. 2002, Nakai et al. 2010, Kaneko et al. 2012).

\section{Factors affecting the outcome of testis tissue xenografting}

\section{Effect of donor species on the success and efficiency of spermatogenesis}

So far, to our knowledge, 23 species of mammals (three primates, two rodents, one lagomorph, four carnivores and 13 ungulates) belonging to 15 families classified in six orders have been used as donors for testicular tissue xenografting (Table 1). Testis tissue of all species with the exception of the marmoset (Schlatt et al. 2002) replaced the castrated host with androgens, indicating that not only the spermatogenic but also the steroidogenic function of the testicular tissue is restored in the grafts. Only one report mentioned low production of testosterone when human testis was subjected to grafting
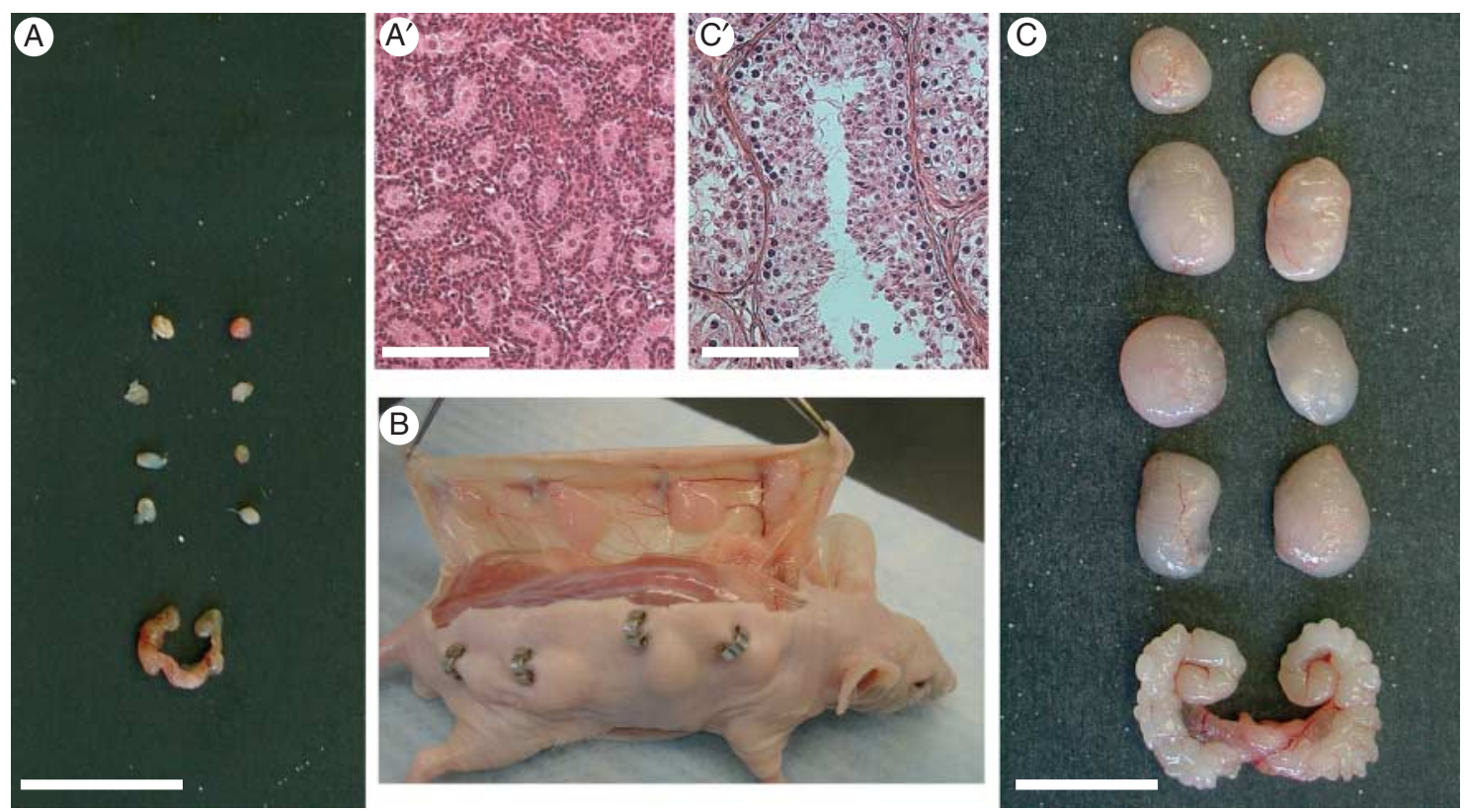

Figure 1 Xenografting of testis tissue from lambs under the skin of nude mice. (A) The size of lamb testis grafts before grafting and seminal vesicle of castrated host mouse and $\left(\mathrm{A}^{\prime}\right)$ histological appearance of donor tissue showing gonocytes. (B) Dorsal and ventral view of the skin of mouse with xenografts 12 weeks postgrafting. (C) The size of lamb testis grafts and seminal vesicle of host mouse 16 weeks after grafting and ( $\left.C^{\prime}\right)$ histological appearance of graft tissue showing elongated spermatids. Scale bar: A and C, 1 cm; A' and C', $100 \mu \mathrm{m}$. 


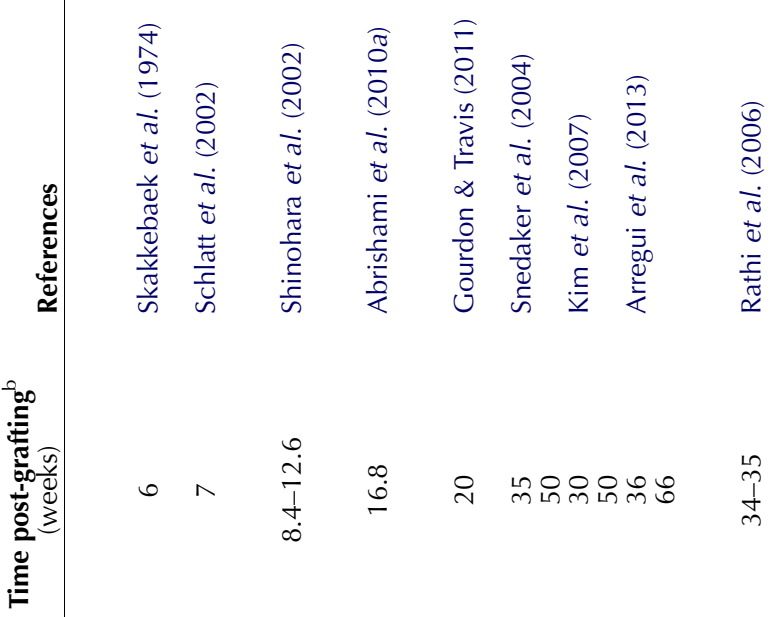

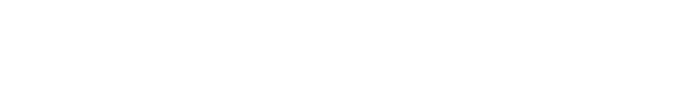




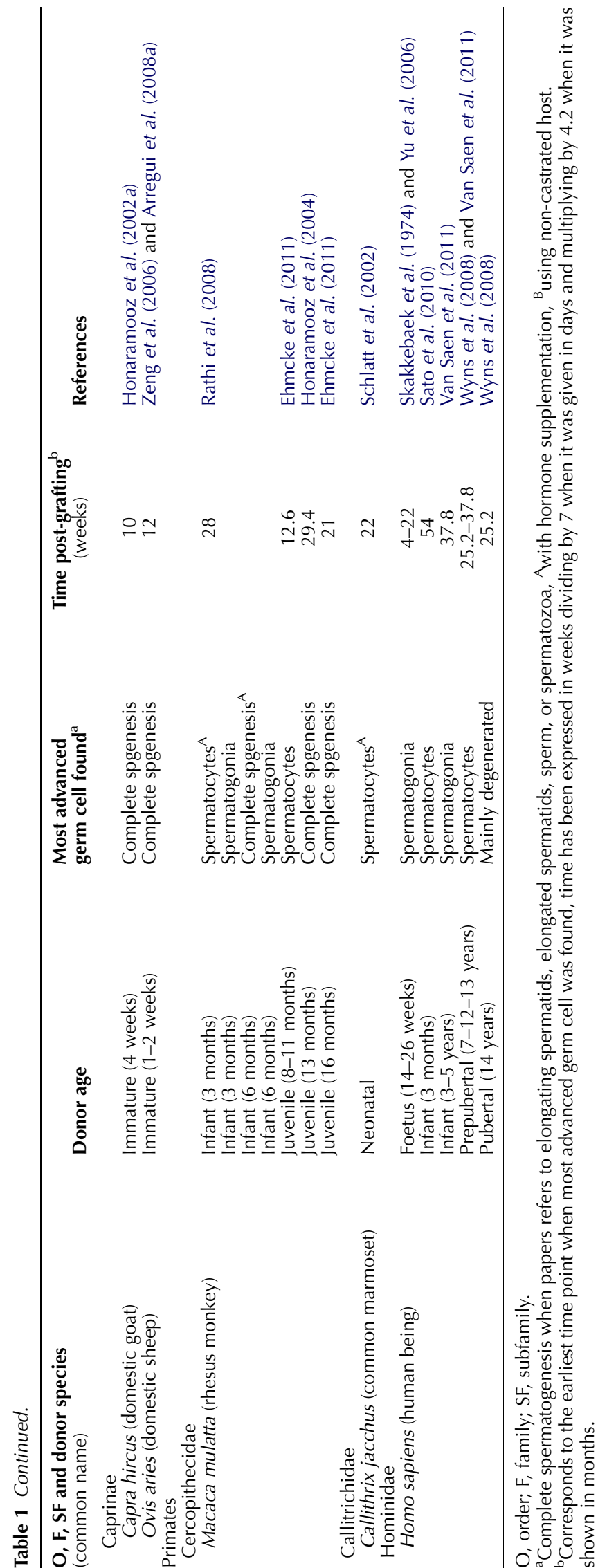

(Sato et al. 2010). Also, in most cases, germ cells survive and complete spermatogenesis showing applicability of this technique across a wide range of mammals. In 16 out of the 23 species testicular xenografting has been used, which lead to complete spermatogenesis. We have considered complete spermatogenesis when presence of elongating spermatids, elongated spermatids, sperm or spermatozoa were reported by the authors. However, possibly, in the remaining species, timing of spermatogenesis plays an important role, as round spermatids were observed as the most advanced germ cells in some cases (Arregui et al. 2013). This will be discussed in the next section.

Interestingly, the efficiency of spermatogenesis, which is measured as the percentage of tubules presenting complete spermatogenesis, widely varied among species. This parameter is difficult to compare as most studies have been designed to find the sperm. Although several studies have shown that the percentage of tubules showing complete spermatogenesis increases with time (Rathi et al. 2005, Arregui et al. 2008a, Kaneko et al. 2008, Abbasi \& Honaramooz 2012), few experiments recovered the testicular tissue at different time points after completion of spermatogenesis. Pig, goat or sheep xenografts presented $50-60 \%$ of seminiferous tubules with complete spermatogenesis, or a high-sperm concentration $\left(60-100 \times 10^{6} \mathrm{sperm} / \mathrm{g}\right)$ has been isolated from grafts (Honaramooz et al. 2002a, Zeng et al. 2006). Conversely, bull or horse testicular tissue showed $<10 \%$ tubules in sperm after xenografting (Oatley et al. 2004, 2005, Rathi et al. 2005, 2006, Huang et al. 2008).

Induction and maintenance of spermatogenesis require a continuous and controlled interaction of several hormones in the hypothalamic-pituitary-testis axis. Interestingly, a coordinated hormonal interaction is established between the host mouse's hypothalamus and pituitary and the transplanted gonad that induces and maintains active spermatogenesis in the transplanted tissue. In most species, Sertoli cells and Leydig cells present in donor tissue were able to respond to mouse gonadotrophin stimulation as Sertoli cell proliferation, maturation (Rathi et al. 2008) and full spermatogenesis have been confirmed (Table 1). The mechanism underlying the consistent progression of spermatogenesis in grafted testicular tissue from different species and species-specific differences in the efficiency of spermatogenesis after grafting remain unknown.

Differences in spermatogenic efficiency could be due to similarities or differences of gonadotrophins between species. Pituitary gonadotrophins (follicle-stimulating hormone (FSH) and luteinising hormone (LH)) as other gonadotrophins (thyroid-stimulating hormone and CG) are glycoproteins consisting two dissimilar subunits linked non-covalently, named $\alpha$ subunit and $\beta$ subunit. Both subunits are similar among mammals. Alpha subunits present uniformity in primary and secondary structures and can be interchangeable between 
vertebrate species obtaining active hormones (with an exception in one mammal: the equine $\beta$ subunit needs an equine $\alpha$ subunit but the equine $\alpha$ subunit can combine with $\beta$ subunits from other species). Beta subunits define the activity of the protein and, although not as highly conserved as $\alpha$ subunits, present a high degree of sequence homology among species (Bousfield et al. 2006). However, other differences, such as pattern of glycosylation, not in amino acid sequence could modulate binding affinity between receptor and ligand (Bousfield et al. 1996). It could be speculated that similarities among gonadotrophins allow interaction between mouse hormones and donor testicular tissue receptors, but dissimilarities cause inefficiency in this interaction. On the other hand, it has been found that the Platyrrhini lineage (New World monkeys), which has the common marmoset, presents a unique type of $\mathrm{LH}$ receptor with exon 10 missing in the mRNA (Gromoll et al. 2003). This makes marmoset cells insensitive to mouse $\mathrm{LH}$, leading to blockage of germ cell differentiation during testicular xenografting (Wistuba et al. 2004). However, increasing testosterone concentration by cografting with hamster tissue, supplementation with human chorionic gonadotrophin or testicular tissue autotransplantation did not overcome spermatogenic arrest in this species (Wistuba et al. 2004, 2006). In the common marmoset, complete spermatogenesis has only been achieved after orthotopic (in the scrotum) autografting, while higher temperature under the mouse skin might contribute to spermatogenic arrest in ectopic grafts (Luetjens et al. 2008).

In addition, the role of testosterone on the negative feedback should be considered, although the sequence and function of this hormone is highly conserved among vertebrates. Bovine xenografts produce large amount of testosterone, which is evidenced by presence of larger seminal vesicles in recipient mice than in control mice (Rathi et al. 2005). However, in bovine xenografts, hormone supplementation to decrease androgen production and delay Sertoli cell maturation did not increase the percentage of tubules with differentiated germ cells (Rodriguez-Sosa et al. 2012).

Among vertebrates, testicular xenografting has been published only in mammalian species. Since the organisation and regulation of spermatogenesis is similar in all amniotes, it might also work in birds and reptiles. Other tissues (such as skin) from birds and reptiles xenografted into mice survive (Reed \& Manning 1978). However, at least in the case of birds, the role of temperature should be considered as spermatogenesis takes place at higher temperatures than in mammals (Beaupré et al. 1997). To our knowledge one attempt has been made using avian testicular tissue. Two months after grafting, spermatogonia were found in chicken testis xenografts but spermatogenesis did not proceed further (G Fernandez de Avelar, personal communication).

\section{Effect of donor age on the success and efficiency of spermatogenesis}

A clear effect of donor age at the time of grafting has been shown to occur in immature testis tissue having much better developmental potential for xenografting than in adult testis tissue. Xenografting has been performed using adult testicular tissue of 11 species and most studies indicated degeneration of grafted tissue (Table 2). We have considered testicular degeneration when authors found hyalinised or sclerotic tissue or mentioned to observe degenerated tissue. However, germ cell and graft survival are less dependent on the absolute age of the tissue than on the state of spermatogenesis at the time of grafting. Progression of tissue degeneration has been related with the degree of presence of spermatozoa, intensity of sperm production for the species and on the efficiency of spermatogenesis of the tissue at the time of grafting. Xenografted tissue presenting a high percentage of spermatozoa and from a species with high sperm production degenerates faster. In addition, species-specific differences have been found, but the reasons have not been resolved so far (Arregui et al. 2008b). Different hypotheses have been proposed to explain the different potential of immature vs mature testis tissue to survive after grafting with a different sensitivity to hypoxia the most likely (Schlatt et al. 2002, Yu et al. 2006, Arregui et al. 2008b, 2012). Degeneration of mature testicular tissue has been demonstrated not to be inherent to the adult tissue as suppression of spermatogenesis in adult mouse testis prior to allografting supports resurgence of spermatogenesis (Arregui et al. 2012).

Immature tissue at different ages has been used as donor tissue showing that neonatal, infant, juvenile and prepubertal tissue complete spermatogenesis when xenografted (Table 1). Young, sexually immature donors seem to present higher efficiency of spermatogenesis after xenografting than newborn testis tissue in bulls, cats and pigs (Oatley et al. 2005, Kim et al. 2007, Caires et al. 2008). It has been proposed that the closer the tissue is to puberty the highest concentration of spermatogonia is found (Orwig \& Schlatt 2005). Thus, more spermatogonia survive the grafting procedure allowing the presence of stem cells in more seminiferous tubules and finally, showing a higher efficiency of spermatogenesis. Also, it has been suggested that a different responsiveness to mouse gonodatrophins exist among infant, juvenile and prepubertal monkey testis (Rathi et al. 2008). Finally, differential gene expression could be modulating graft growth and germ cells differentiation between bull calves of different ages (Schmidt et al. 2007).

Results published so far on xenografting of foetal testicular tissue showed the presence of spermatogonia in humans and spermatocytes in bovine and Cuvier's gazelle (Povlsen et al. 1974, Skakkebaek et al. 1974, Yu et al. 2006, Rodriguez-Sosa et al. 2011, Arregui et al. 


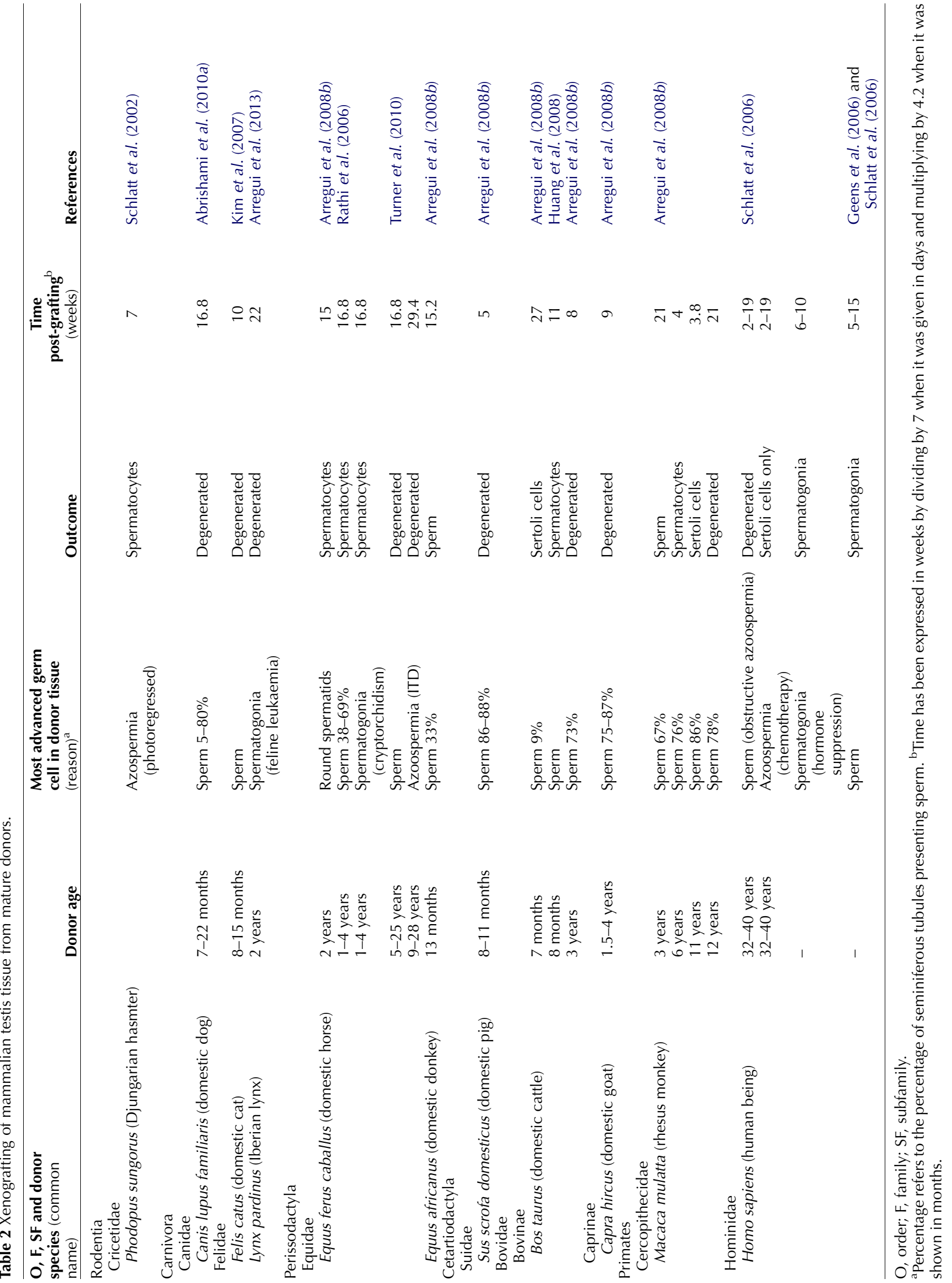


2013). It could be speculated that spermatogenesis will proceed further with longer incubation post-grafting, but haploid germ cells have not been found in prenatal testicular grafts so far to our knowledge.

\section{Differences in timing of spermatogenesis related with species and age of donor}

Early in puberty, gonocytes migrate to the periphery of the seminiferous tubules, contact the basal lamina and differentiate into spermatogonia which will enter into the first wave of spermatogenesis. It has been suggested that, after grafting, differentiated germ cells present in the tissue degenerate and spermatogenesis restarts from surviving the spermatogonia (Rathi et al. 2006, Kim et al. 2007). Time required for the completion of the first wave of spermatogenesis in the transplanted testicular tissue is called the timing of spermatogenesis and it is has been compared between grafts and the donor testis in situ.

Spermatogenesis in xenografted tissue appears to occur according to the kinetics of the donor as has been proposed in rabbit, bull, bison, ferret and alpaca (Shinohara et al. 2002, Oatley et al. 2004, 2005, Rathi et al. 2005, Abbasi \& Honaramooz 2011a, Gourdon \& Travis 2011, Elzawan 2013). Nevertheless, results has been inconsistent between different studies with some other species namely cat, pig and sheep. While some studies found similar timing to controls in cat and pig (Snedaker et al. 2004, Kaneko et al. 2008) others proposed it to be longer in cat (Kim et al. 2007) and shorter in the case of pig (Honaramooz et al. 2002a). In addition, it has been suggested to be shorter in rhesus monkey, humans and collared peccary (Honaramooz et al. 2004, Sato et al. 2010, Campos-Junior et al. 2013). In sheep, grafting of immature testicular tissue appeared to accelerate the onset of spermatogenesis (Dobrinski et al. 2003, Zeng et al. 2006), but further studies demonstrated that the observed effects were due to differences in the source of control tissue and not in the time needed to reach complete spermatogenesis (Arregui et al. 2008a). Similarly, studies in boar xenografts showed similar timing for complete spermatogenesis although different studies suggested different conclusions (Honaramooz et al. 2004, Kaneko et al. 2008; Table 1). Also, spermatogenesis takes place more uniformly in the testis in situ than in xenografts. Control tissue is histologically more homogeneous among seminiferous tubules, while graft tissue showed asynchronous development with seminiferous tubules in sperm next to tubules without differentiated germ cells (Oatley et al. 2004, 2005, Kim et al. 2007, Arregui et al. 2008a, Rathi et al. 2008). By contrast, in rhesus monkey testis tissue xenografting clearly accelerated the maturation of the testicular tissue. The grafts from juvenile monkeys (13 months old) presented sperm 7 month posttransplantation, while spermatogenesis in situ usually initiates at 3-4 years of age in this species (Honaramooz et al. 2004). Correspondingly, hormone stimulation of juvenile rhesus monkeys (15-16 months old) to mimic adulthood induces the onset of precocious puberty and initiation of spermatogenesis at 19-22 months of age (Plant et al. 1989). Early maturation of immature tissue when exposed to a mature hormonal milieu could be responsible for the proposed shorter timing of spermatogenesis in tissue grafts from humans and collared peccary (Sato et al. 2010, Campos-Junior et al. 2013), but this has not been critically analysed in any species other than rhesus monkey. Primate species are good models to study the effect of modulation of the hormone microenvironment as they reach sexual maturity later than other species.

Accordingly, it has been proposed that manipulation of the endocrine environment in the mouse host could aid to shorten the time span required for sperm production (Dobrinski 2005). Treatment of host mouse with exogenous gonadotrophins stimulated tissue maturation in grafts from infant rhesus monkeys and accelerated spermatogenesis in horse testis tissue grafts (Rathi et al. 2006, 2008), but administration of FSH to mice carrying human testis xenografts did not shorten the timing to spermatogenesis (Van Saen et al. 2013). Likewise, the use of sexually intact recipient mice maintaining high testosterone levels resulted in earlier onset of spermatogenesis in water buffalo testis grafts (Reddy et al. 2012), but did not accelerate germ cell differentiation in bull or pig testis grafts (Huang et al. 2008, Abbasi \& Honaramooz 2010).

When considering the effect of donor species on the timing of spermatogenesis, the maturation status of the donor tissue should also be taken into account. Similar timing has been found with neonatal and prepubertal testicular tissue in cats and cattle (Snedaker et al. 2004, Oatley et al. 2005, Rathi et al. 2005, Kim et al. 2007, Huang et al. 2008). However, usually, grafts from different aged donors were recovered at the same time points without considering these differences of the tissues at the time of grafting.

Spermatogenesis in transplanted tissue has been proposed to reinitiate from remaining spermatogonial stem cells (Rathi et al. 2006, Kim et al. 2007). Also, the duration of the cycle of the seminiferous epithelium in xenografts has been shown to be similar to the duration in situ (Zeng et al. 2006). Therefore, differences between species appear to be inherent to the germ cell genotype and could result in different sensitivity to endogenous and exogenous hormones but further studies are needed.

To our knowledge, spermatocytes are the most advanced germ cells found in prenatal testicular grafts, but they appeared later than in post-natal tissue grafts. Bovine and gazelle fresh foetal tissue survived and spermatogenesis proceeded to the spermatocyte stage 10 and 15 months post-grafting respectively (RodriguezSosa et al. 2011, Arregui et al. 2013) while haploid germ 
cell are found at similar time point in young bovine testicular xenografts (Rathi et al. 2005). An initial loss of germ cells was noticed after grafting (Rathi et al. 2005, 2006, Arregui et al. 2008a). This loss could be more pronounced in foetal tissue as prenatal testes presented a lower number of spermatogonia per seminiferous tubule, causing a delay in the timing of spermatogenesis (Arregui et al. 2013).

Most studies have focused on the earliest time point when sperm can be retrieved. However, the percentage of seminiferous tubules presenting complete spermatogenesis in grafted tissue increased with time in cattle, sheep, pig and deer (Rathi et al. 2005, Arregui et al. 2008a, Kaneko et al. 2008, Abbasi \& Honaramooz 2012). Interestingly, it has been suggested that fertility competence decreased in porcine xenogeneic spermatozoa obtained from old grafts probably due to a negative effect of accumulated sperm that suffer senescence due to the lack of excurrent ducts in grafted tissue (Honaramooz et al. 2008). Therefore, the optimal time window to recover the grafted tissue has to be determined as a tradeoff between the highest amount of mature sperm and the highest fertilising ability.

\section{Influence of recipient mice}

Mainly immunodeficient nude mice have been used as host mice for testis tissue xenografting (for instances in studies show in Table 1 only Kim et al. (2007) and Campos-Junior et al. (2013) do not use nude mice). Nude mice lack a functional thymus and therefore are deficient in T-lymphocytes (Pelleitier \& Montplaisir 1975). Similarly, severe combined immunodeficient (SCID) mice are athymic, but they also lack B-lymphocytes (Bosma et al. 1983). Some experiments proclaimed that both recipient strains are suitable for this technique (Snedaker et al. 2004, Rathi et al. 2005, 2006, Schlatt et al. 2006), but it was hypothesised that SCID mice may provide a more suitable host environment for the development of xenografts as they present a higher severity of immunodeficiency. No differences between the two strains were found when mouse prepubertal testicular tissue was allografted (Geens et al. 2006). However, the possible difference due to different subcutaneous temperature has not been kept in mind when using a naked (nude) or haired (SCID) mouse as a host. Only one recent study has systematically compared the outcome of porcine testis tissue xenografting using both strains of mice. The results showed that the percentage of recovered grafts, graft weight, seminiferous tubular density and percentage of tubules cross sections presenting germ cells were higher when SCID mice were used as hosts while no differences were found in the percentage of tubules with elongated or round spermatids (Abbasi \& Honaramooz 2010). It could be interesting to analyse whether these results are maintained when using another species as donor for the testicular tissue. Also, it has to be considered that the percentage of tubules presenting haploid germ cells did not differ between strains and, therefore, when the objective is to obtain sperm, nude and SCID are equally valid as host mice.

One of the most examined issues related to the recipient mice is the role of host castration. It has been demonstrated that following castration, $\mathrm{FSH}$ and $\mathrm{LH}$ release from the pituitary increased markedly (Swerdloff et al. 1971) due to the loss of inhibition from testicular hormones. After revascularisation, exposure to elevated levels of FSH has been suggested to stimulate Sertoli cells proliferation in the grafted tissue, and LH secretion supports Leydig cell maturation and subsequent production of testosterone needed for spermatogenesis to occur. Subsequently, pituitary hormone levels decrease to pre-castration levels. Therefore, using a gonadectomised male mouse has been proposed to be essential for the success of testicular transplantation, but differences between species have been found. While immature tissue from rhesus monkey did not develop in noncastrated recipients (Honaramooz et al. 2004), testis grafts from other species completed spermatogenesis (Shinohara et al. 2002, Huang et al. 2008, Abbasi \& Honaramooz 2010, Schlatt et al. 2010b, Reddy et al. 2012). The percentage of recovered grafts from water buffalo tissue was lower and more degenerated seminiferous tubules were found but the onset of spermatogenesis appeared to be shorter when using intact host mice (Reddy et al. 2012). However, no difference in outcome has been observed between using castrated or intact mice for transplantation of xenografts from cattle, pig and hamster testis (Huang et al. 2008, Abbasi \& Honaramooz 2010, Schlatt et al. 2010b).

In addition, female and male nude mice have been compared as recipients for testicular xenografts. In female recipients, grafts were smaller, the percentage of recovered grafts was lower and less seminiferous tubules with haploid germ cells could be found (Abbasi \& Honaramooz 2010). Also, the effect of single and group housing of nude host mice has been analysed, as social hierarchy between males correlates with serum androgen levels and reproductive parameters. However, no effect was found in the percentage of recovered grafts, percentage of tubules with differentiated germ cells nor in the weights of grafts and seminal vesicle from host mice (Arregui et al. 2008a). Finally, aged nude host mice transplanted with testis tissue from newborn hamster showed more tubules with germ cells and haploid germ cells than young recipients probably due to immunosenescence in older recipients (Ehmcke et al. 2008). But, using 1-year-old mice may not be suitable if the objective is to obtain sperm, as the remaining lifespan could be insufficient for complete tissue maturation and germ cell differentiation.

Taking all these results together, castrated nude or SCID male mice appear to be the suitable hosts for testicular tissue xenografting. 
The maximal lifespan of nude mice is $\sim 1.5$ years (Honaramooz et al. 2004) and shorter for SCID (JAX 2000). This fact could preclude reaching complete spermatogenesis in some species (Sato et al. 2010) when timing of spermatogenesis is conserved. However, as discussed in previous sections, onset of spermatogenesis is shortened in grafts from some species and it could be accelerated by hormonal supplementation in others. Further studies are required to test whether complete spermatogenesis can be achieve when using species taking long periods until sexual maturity, as has been shown in rhesus monkey (Honaramooz et al. 2004, Rathi et al. 2008). Also, survival is lower in immunocompromised mice than in WT and although some studies kept mice for more than a year (Honaramooz et al. 2002a, Arregui et al. 2013) most of them commented that some mice became ill or died before the selected time point for being killed (Snedaker et al. 2004, Arregui et al. 2008a, Abbasi \& Honaramooz 2010, 2011a,b, 2012, Abrishami et al. 2010a, Sato et al. 2010). SCID mice have a high lymphoma incidence and both strains present increased susceptibility to opportunistic organism (JAX 2000).

\section{Does donor tissue preservation affect tissue survival and differentiation?}

Xenografting has been mainly performed using fresh donor tissue, but refrigerated and cryopreserved testicular tissues have also been used showing comparable graft survival and sperm production. Pig, cat and rhesus monkey testicular xenografts retained high cell viability and similar developmental potential after refrigeration of whole testes at $4{ }^{\circ} \mathrm{C}$ for 1,2 or more days (Honaramooz et al. 2002a, Jahnukainen et al. 2007, Zeng et al. 2009, Abrishami et al. 2010b, Mota et al. 2012). Interestingly, refrigeration appeared to increase the percentage of seminiferous tubules with differentiated germ cells and it has been hypothesised that cooling decreased the rate of metabolism, thereby decreasing damage due to the hypoxic environment during xenografting (Jahnukainen et al. 2007, Abrishami et al. 2010b, Abbasi \& Honaramooz 2011a). In addition, different protocols for slow-freezing have been tested using pig, rabbit, monkey, human, cat, lynx and gazelle testes showing, in most cases, preservation of germ cells and differentiation potential (Honaramooz et al. 2002a, Shinohara et al. 2002, Jahnukainen et al. 2007, Wyns et al. 2008, Zeng et al. 2009, Abrishami et al. 2010b, Van Saen et al. 2011, Arregui et al. 2013). However, cat testis tissue cryopreserved using DMSO 1.4 M failed to produce grafts in germ cells (Mota et al. 2012). Also, cryopreservation has been proposed to delay the initiation of spermatogenesis and increase the percentage of seminiferous tubules presenting only Sertoli cells, suggesting that germ cells are highly susceptible to cryoprotective agents and freezing (Jahnukainen et al. 2007, Zeng et al. 2009).
Finally, vitrification protocols for testicular tissue cryopreservation have been applied resulting in tissue survival and differentiation in porcine and maintenance of spermatogonia proliferation capability in rhesus monkey testis grafts (Zeng et al. 2009, Abrishami et al. 2010b, Poels et al. 2012).

Adequate storage of testicular tissue before xenografting is of interest for the application of this technique for fertility recovery as recipient animals may not be immediately available or donor-derived spermatozoa may be desired at a later time (Zeng et al. 2009). Results showed that protocols for tissue storage could be species specific and vary with tissue maturation (Abrishami et al. 2010b, Mota et al. 2012, Arregui et al. 2013). Also, fresh and frozen tissue presenting similar viability develop differently after grafting, demonstrating that germ cell differentiation should be evaluated in addition to cell viability when optimising freezing protocols. Grafting is currently the only functional assay to assess the developmental potential of testis tissue in vivo (Zeng et al. 2009). Further, spermatozoa collected from xenografts can be successfully cryopreserved (Zeng et al. 2009) and therefore fertilisation capability of sperm obtained after xenografting of frozen tissue and cryopreserved spermatozoa harvested after xenografting of fresh tissue should be compared to select an adequate long-term storage protocol.

\section{Current status: where to?}

In the last 5 years, significant progress has been made in testicular tissue xenografting. However, gaps in knowledge remain as outlined above and further studies are required for understanding the determinants of xenograft success and failure.

One of the main problems when using this approach is the low percentage of tubules showing complete spermatogenesis. A high heterogeneity of tubular development has been observed in all species studied to date (Oatley et al. 2004, 2005, Kim et al. 2007, Arregui et al. 2008a, Rathi et al. 2008). Seminiferous tubules presenting sperm could be found adjacent to others without differentiated germ cells. Also, the lumen of some tubules becomes over expanded and the seminiferous epithelium is reduced precluding spermatogonial differentiation (see Fig. 1 in Arregui et al. (2008a)). In addition, the percentage of tubules with every type of germ cell is not consistent among grafts in the same host.

The period of hypoxia following the transplantation procedure is critical for the success of the technique. The lack of uniformity in diffusion and new vessel development could be responsible for differential availability of factors supporting cell maturation and survival. Maturation of Sertoli cells and spermatogonia/gonocyte survival could play a major role in this asynchronous development and low efficiency of spermatogenesis. Therefore, protocols that reduce tissue stress induced 
by grafting should be developed and this lack of uniformity inside the tissue should be studied for further improvement of testis tissue xenografting. As previously mentioned testis tissue refrigeration seems to increase the percentage of tubules with differentiated germ cells (Jahnukainen et al. 2007, Abrishami et al. 2010b, Abbasi \& Honaramooz 2011a). In addition, tissue treatment with vascular endothelial growth factor before grafting increased the percentage of seminiferous tubules presenting complete spermatogenesis (Schmidt et al. 2006).

Another key and only slightly studied topic is the viability and normality of offspring using sperm derived from xenografts. Fertilising capability after ICSI of spermatozoa retrieved from xenografts has been compared with testicular, epididymal or ejaculated sperm in pigs, monkeys or dogs showing some differences (Honaramooz et al. 2004, 2008, Nakai et al. 2009, Shirazi et al. 2014), which need to be explained. Moreover, although some studies claimed that progeny is fertile or showed normal reproductive ability (Shinohara et al. 2002, Kaneko et al. 2012), results are still limited and other parameters such as phenotype, behaviour, health or senescence should be considered.

\section{Applications of testis tissue xenografting}

Different applications have been described previously and suggested for testicular tissue transplantation (Orwig \& Schlatt 2005, Rodriguez-Sosa \& Dobrinski 2009, Wyns et al. 2010) and have been achieved in the last years.

\section{System to study testis function and pathology}

Xenografts are representative of functional testis tissue in the donor. The duration of the cycle of the seminiferous epithelium was compared by labelling with bromodeoxyuridine, showing that the kinetics of spermatogenesis is conserved in porcine and ovine xenografts (Zeng et al. 2006). Also gene expression has been examined with microarray analysis in pig testis xenografts and was comparable with testis tissue in situ (Zeng et al. 2007). Therefore, grafting can be considered as a valid strategy to explore testicular development and physiology. Ectopic xenografting of hamster testicular tissue into aged or young recipients has been used to assess whether testicular ageing is related with senescence of somatic or germ cells (Ehmcke et al. 2008). Similarly, testicular xenotransplantation was used to elucidated whether spermatogenesis and steroidogenic activity is controlled by intra- or extratesticular factors by modulating the number of hamster grafts and castration of recipient mice (Schlatt et al. 2010b). Also, exogenous spermatogonial stem cells transplanted into a lamb testis before tissue xenografting survived and colonised the niche, confirming that xenografts could be used to study the effect of altered gene expression on testis function (Rodriguez-Sosa et al. 2010). For this reason, testicular xenografting constitutes a model to study i) the gonadotoxicity of drugs and other agents on testicular function and it has been applied to humans or other primates (as a model for humans). Doses of busulfan are clinically used for marrow ablation before bone marrow transplantation or peripheral stem cell rescue. Treatment of host mice with busulfan eliminates differentiating germ cells and decreases the percentage of seminiferous tubules presenting type B spermatogonia in testicular grafts from juvenile rhesus monkeys. These findings are comparable with the pattern found after testicular irradiation in monkeys, suggesting that the effect on xenografts would correspond well to the testicular effect expected after busulfan doses used clinically (Jahnukainen et al. 2006). Mice carrying rat foetal testis xenografts treated with phthalates exhibited suppressed steroidogenesis similar to what was shown after exposure of foetal rats in utero, whereas there was no evidence of endocrine disruption by phthalates in human foetal testis xenografts (Heger et al. 2012, Mitchell et al. 2012). Similarly, using a xenograft approach, it has been demonstrated that exposure of human foetal testis to diethylstilbestrol does not reduce testosterone production (Mitchell et al. 2013). Also, testis xenografting could be used to analyze the ii) pathophysiology of testicular tissue. In horses testicular xenografting has been use to examine cryptorchidism and idiopathic testicular degeneration (ITD). Grafts showed that suppressed spermatogenesis due to cryptorchidism could be reversed as it involves an extra testicular cause while the defect in ITD lies within the testis and not with a primary endocrine deficiency (Turner et al. 2010). In addition, testis tissue allotransplantation is a novel experimental approach to study germ cell development or recover functional spermatozoa from animals with iii) poor viability or neonatally lethal phenotypes (Ohta \& Wakayama 2005, Zeng et al. 2011). In addition, this approach allows accessibility to the tissue to manipulate spermatogenesis and steroidogenesis. Ectopic xenografting has been used to analyse whether infant monkey testes respond to high levels of gonadotropins and spermatogenic differentiation can be accelerated without a juvenile phase of low levels of gonadotrophins (Rathi et al. 2008). Also, the mouse endocrine milieu has been manipulated to try to increase spermatogenic efficiency of bovine (Rodriguez-Sosa et al. 2012) and rhesus monkey xenografts (Ehmcke et al. 2011).

\section{Fertility recovery}

As show in previous sections, testis tissue xenografting is a powerful tool for the recovery of fertility in young individuals, and testicular cryopreservation offers a strong complement for the application of this technique. 
Mainly this approach has two potential applications: the fertility preservation of human childhood cancer patients and of endangered species or valuable livestock. Prepubertal male cancer patients undergo treatments that can prove toxic to the gonads and could lead to permanent infertility of the patient. The role of testicular xenografting for fertility preservation in boys have been widely reviewed (Wyns et al. 2010, Valli et al. 2014) and therefore will not be discuss in this review.

Survival of young animals of wild and captive populations is often low and this represents a significant problem for endangered species and valuable livestock conservation. In small populations, each individual genotype is highly valuable. Testicular tissue xenografting could provide an opportunity to rescue the genetic information of an immature male that died accidentally. Successful generation of offspring using xenogenic spermatozoa from that male could have a significant impact on the genetic diversity within a population. So far, testes from four endangered species have been xenotransplanted. Spermatogonia but no differentiated germ cells were found in Iberian lynx testis grafts more than 1 year post-grafting, spermatocytes were present in Javan Banteng and Cuvier's gazelle grafts while xenografted tissue from Mohor gazelles contained round spermatids (Honaramooz et al. 2005, Arregui et al. 2013). Tissue handling and time from tissue collection to grafting could be critical for successful xenografting in endangered species. On the other hand, it is crucial that the development of other assisted reproductive techniques, such as in vitro maturation of oocytes, ICSI and embryo transfer for the target species, is in place for the applicability of this strategy in endangered species and breeds.

Also xenografting of testicular tissue could offer an option for fertility recovery in cryptorchid animals. When testes do not descent into the scrotum and are therefore kept at core body temperature spermatogenesis is abolished. Testis tissue from cryptorchid horses was restored to full spermatogenesis when grafted into immunocompromised mice even after years (1-3 years) of exposure to core body temperature. This experiment demonstrated that, at least in horses, germ cells present in cryptorchid testes retain their developmental potential (Turner et al. 2010).

To conclude, testicular tissue banking must be considered as a priority and all the information compiled here should encourage oncologists and people working with rare and endangered species (in zoos, captive breeding centres and farms) to consider the cryopreservation of testicular tissue from young patients or animals when possible.

\section{Comparison with other techniques}

Currently, different methods of in vivo and in vitro spermatogenesis are being developed in mammals. So far, two in vitro culture systems have been successful in obtaining spermatozoa very recently: the culture of testicular tissue fragments (Sato et al. 2011) and the testicular three-dimensional (3D) cell culture (Stukenborg et al. 2009, Abu Elhija et al. 2012). Conventional testicular cell culture in cell suspensions has not been able to provide complete spermatogenesis, demonstrating the need for maintaining the spatial structure of this complex organ (Dores et al. 2012). When a single-cell suspension is allowed to reaggregate in a 3D extracellular matrix, mimicking the culture of testis pieces, complete differentiation into spermatozoa has been found. Both systems support the testicular architecture and the paracrine environment, but eliminate the endocrine signalling. These approaches could become appropriate for production of spermatozoa, as they allow for a better control of spermatogenesis than testicular xenografting eliminating the possible effect of the mouse host. However, as novel techniques, the development of protocols for translation of these technologies to mammalian species other than mouse might need to be accomplished. In addition, the physiology of testicular tissue in culture, outside its natural environment and lacking blood supply, should be compared with the testes in vivo to demonstrate whether these approaches could be used as models to study testicular function. Probably these systems will not be appropriate for that purpose.

Another technique of in vivo spermatogenesis could be used for the same applications similar to testicular tissue xenotransplantation. Subcutaneous xenografting of rat, pig, sheep and peccary testicular cell suspensions formed functional testicular tissue. This procedure could be used to study testicular morphogenesis and cell interactions, but the onset of spermatogenesis is delayed when compared with xenotransplantation of testicular fragment (Gassei et al. 2006, Honaramooz et al. 2007, Arregui et al. 2008a, Campos-Junior et al. 2013). Finally, germ cell transplantation into the seminiferous tubules could be used for the production of sperm from genetically close species (Dores et al. 2012). For large mammals, germ cell transplantation has been only performed between individuals of the same species (Honaramooz et al. 2002b, 2003, Kim et al. 2006). Autotransplantation of germ cell in humans after cancer treatment could be a possibility in the future once cellsorting methods guarantee to be efficient enough to avoid the risk of reintroducing cancer cells into the patient. For endangered species, the phylogenetic distance to a domesticated or available model could preclude the success of germ cell transplantation. However, for rare or valuable breeds germ cell transplantation could be an option for fertility recovery.

\section{Conclusions}

Currently, testis tissue xenografting is a unique system that allows study of testicular maturation and function 
and, at the same time, obtaining fertilisation competent spermatozoa from immature testicular tissue from several mammalian species. Different factors have been shown to influence the outcome of testicular tissue xenotransplantation. The percentage of tubules presenting differentiated germ cells in the grafted testicular tissue is affected by: i) the donor tissue species, ii) the donor tissue age, iii) the time post-grafting, iv) the method for tissue preservation before xenografting and v) the characteristics of the recipient mice.

\section{Declaration of interest}

The authors declare that there is no conflict of interest that could be perceived as prejudicing the impartiality of the review.

\section{Funding}

Work from the Dobrinski laboratory cited in this review was funded in part by NIH/ORIP grant 5 R01 OD016575-13.

\section{References}

Abbasi S \& Honaramooz A 2010 Effects of recipient mouse strain, sex and gonadal status on the outcome of testis tissue xenografting. Reproduction, Fertility, and Development 22 1279-1286. (doi:10.1071/RD10084)

Abbasi S \& Honaramooz A 2011 a Xenografting of testis tissue from bison calf donors into recipient mice as a strategy for salvaging genetic material. Theriogenology 76 607-614. (doi:10.1016/j.theriogenology. 2011.03.011)

Abbasi S \& Honaramooz A $2011 b$ The number of grafted fragments affects the outcome of testis tissue xenografting from piglets into recipient mice. Veterinary Medicine International 2011. Article ID: 686570. (doi:10. 4061/2011/686570)

Abbasi S \& Honaramooz A 2012 Feasibility of salvaging genetic potential of post-mortem fawns: production of sperm in testis tissue xenografts from immature donor white-tailed deer (Odocoileus virginianus) in recipient mice. Animal Reproduction Science 135 47-52. (doi:10.1016/j.anireprosci.2012.09.007)

Abrishami M, Abbasi S \& Honaramooz A 2010a The effect of donor age on progression of spermatogenesis in canine testicular tissue after xenografting into immunodeficient mice. Theriogenology 73 512-522. (doi:10.1016/j.theriogenology.2009.09.035)

Abrishami M, Anzar M, Yang Y \& Honaramooz A 2010b Cryopreservation of immature porcine testis tissue to maintain its developmental potential after xenografting into recipient mice. Theriogenology 73 86-96. (doi:10.1016/j.theriogenology.2009.08.004)

Abu Elhija M, Lunenfeld E, Schlatt S \& Huleihel M 2012 Differentiation of murine male germ cells to spermatozoa in a soft agar culture system. Asian Journal of Andrology 14 285-293. (doi:10.1038/aja.2011.112)

Arregui L, Rathi R, Megee SO, Honaramooz A, Gomendio M, Roldan E \& Dobrinski I 2008a Xenografting of sheep testis tissue and isolated cells as a model for preservation of genetic material from endangered ungulates. Reproduction 136 85-93. (doi:10.1530/REP-07-0433)

Arregui L, Rathi R, Zeng W, Honaramooz A, Gomendio M, Roldan ERS \& Dobrinski I $2008 b$ Xenografting of adult mammalian testis tissue. Animal Reproduction Science 106 65-76. (doi:10.1016/j.anireprosci.2007. 03.026)

Arregui L, Rathi R, Modelski M, Zeng W, Roldan ERS \& Dobrinski I 2012 Suppression of spermatogenesis before grafting increases survival and supports resurgence of spermatogenesis in adult mouse testis. Fertility and Sterility 97 1422-1429. (doi:10.1016/j.fertnstert.2012.03.009)

Arregui L, Dobrinski I \& Roldan ERS 2013 Germ cell survival and differentiation after xenotransplantation of testis tissue from three endangered species: Iberian lynx (Lynx pardinus), Cuvier's gazelle (Gazella cuvieri) and Mohor gazelle (G. dama mhorr). Reproduction, Fertility, and Development 26 817-826. (doi:10.1071/RD12411)

Beaupré CE, Tressler CJ, Beaupré SJ, Morgan JL, Bottje WG \& Kirby JD 1997 Determination of testis temperature rhythms and effects of constant light on testicular function in the domestic fowl (Gallus domesticus). Biology of Reproduction 56 1570-1575. (doi:10.1095/biolreprod56. 6.1570)

Bosma GC, Custer RP \& Bosma MJ 1983 A severe combined immunodeficiency mutation in the mouse. Nature 301 527-530. (doi:10.1038/ 301527a0)

Bousfield GR, Butnev VY, Gotschall RR, Baker VL \& Moore WT 1996 Structural features of mammalian gonadotropins. Molecular and Cellular Endocrinology 125 3-19. (doi:10.1016/S0303-7207(96)03945-7)

Bousfield GR, Jia L \& Ward DN 2006 Gonadotropins: chemistry and biosynthesis. In Knobil and Neill's Physiology of Reproduction, vol 1, 3rd edn, pp 1581-1634. Eds JD Neill. San Diego: Elsevier Academic Press.

Caires KC, Schmidt JA, Oliver AP, De Avila J \& McLean DJ 2008 Endocrine regulation of the establishment of spermatogenesis in pigs. Reproduction in Domestic Animals 43 280-287. (doi:10.1111/j.1439-0531.2008. 01175.x)

Campos-Junior PH, Costa GM, Avelar GF, Lacerda SS, Costa NN, Ohashi OM, Miranda MS, Barcelos LS, Jorge ÉC, Guimarães DA et al. 2013 Derivation of sperm from xenografted testis cells and tissues of the peccary (T. tajacu). Reproduction 147 291-299. (doi:10.1530/REP-13-0581)

Dobrinski I 2005 Germ cell transplantation and testis tissue xenografting in domestic animals. Animal Reproduction Science 89 137-145. (doi:10.1016/j.anireprosci.2005.06.020)

Dobrinski I, Megee S \& Honaramooz A 2003 Xenografting of testis tissue from neonatal ram lambs into mouse hosts accelerates testicular maturation and sperm production. In 36th Annual Meeting of the Society for the Study of Reproduction, vol. 68, Suppl. 1, abstract 191, Cincinnati, $\mathrm{OH}$, USA.

Dores C, Alpaugh W \& Dobrinski I 2012 From in vitro culture to in vivo models to study testis development and spermatogenesis. Cell and Tissue Research 349 691-702. (doi:10.1007/s00441-012-1457-x)

Eggermont J, Donnez J, Casanas-Roux F, Scholtes H \& Van Langendonckt A 2005 Time course of pelvic endometriotic lesion revascularization in a nude mouse model. Fertility and Sterility 84 492-499. (doi:10.1016/ j.fertnstert.2005.03.034)

Ehmcke J, Gassei K \& Schlatt S 2008 Ectopic testicular xenografts from newborn hamsters (Phodopus sungorus) show better spermatogenic activity in aged compared with young recipients. Journal of Experimental Zoology. Part A, Ecological Genetics and Physiology 309A 278-287. (doi:10.1002/jez.459)

Ehmcke J, Gassei K, Westernströer B \& Schlatt S 2011 Immature rhesus monkey (Macaca mulatta) testis xenografts show increased growth, but not enhanced seminiferous differentiation, under human chorionic gonadotropin treatment of nude mouse recipients. International Journal of Andrology 34 e459-e467. (doi:10.1111/j.1365-2605.2011.01179.x)

Elzawan AZ 2013 Establishment of spermatogenesis following testicular tissue ectopic xenografting in alpaca. PhD Thesis. Washington State University.

Gassei K, Schlatt S \& Ehmcke J 2006 De novo morphogenesis of seminiferous tubules from dissociated immature rat testicular cells in xenografts. Journal of Andrology 27 611-618. (doi:10.2164/jandrol. 05207)

Geens M, de Block G, Goossens E, Frederickx V, van Steirteghem A \& Tournaye H 2006 Spermatogonial survival after grafting human testicular tissue to immunodeficient mice. Human Reproduction 21 390-396. (doi:10.1093/humrep/dei412)

Gourdon JC \& Travis AJ 2011 Spermatogenesis in ferret testis xenografts: a new model. Comparative Medicine 61 145-149.

Gromoll J, Wistuba J, Terwort N, Godmann M, Müller T \& Simoni M 2003 A new subclass of the luteinizing hormone/chorionic gonadotropin receptor lacking exon 10 messenger RNA in the New World monkey (Platyrrhini) lineage. Biology of Reproduction 69 75-80. (doi:10.1095/ biolreprod.102.014902)

Gunn RMC \& Seddon HR 1930 Testicular grafts on rams. Australian Veterinary Journal 6 132-145. (doi:10.1111/j.1751-0813.1930.tb15005.x)

Heger NE, Hall SJ, Sandrof MA, McDonnell EV, Hensley JB, McDowell EN, Martin KA, Gaido KW, Johnson KJ \& Boekelheide K 2012 Human fetal 
testis xenografts are resistant to phthalate-induced endocrine disruption. Environmental Health Perspectives 120 1137-1143. (doi:10.1289/ehp. 1104711)

Honaramooz A, Snedaker A, Boiani M, Schöler H, Dobrinski I \& Schlatt S 2002 a Sperm from neonatal mammalian testes grafted in mice. Nature 418 778-781. (doi:10.1038/nature00918)

Honaramooz A, Megee SO \& Dobrinski I 2002b Germ cell transplantation in pigs. Biology of Reproduction 66 21-28. (doi:10.1095/biolreprod66. 1.21)

Honaramooz A, Behboodi E, Blash S, Megee SO \& Dobrinski I 2003 Germ cell transplantation in goats. Molecular Reproduction and Development 64 422-428. (doi:10.1002/mrd.10205)

Honaramooz A, Li MW, Penedo MC, Meyers S \& Dobrinski I 2004 Accelerated maturation of primate testis by xenografting into mice. Biology of Reproduction 70 1500-1503. (doi:10.1095/biolreprod.103. 025536)

Honaramooz A, Zeng W, Rathi R, Koster J, Ryder O \& Dobrinski I 2005 Testis tissue xenografting to preserve germ cells from a cloned Banteng calf. Reproduction, Fertility, and Development 17 247. (doi:10.1071/ RDv17n2Ab193)

Honaramooz A, Megee SO, Rathi R \& Dobrinski I 2007 Building a testis formation of functional testis tissue after transplantation of isolated porcine (Sus scrofa) testis cells. Biology of Reproduction 76 43-47. (doi:10.1095/biolreprod.106.054999)

Honaramooz A, Cui X, Kim N \& Dobrinski I 2008 Porcine embryos produced after intracytoplasmic sperm injection using xenogeneic pig sperm from neonatal testis tissue grafted in mice. Reproduction, Fertility, and Development 20 802-807. (doi:10.1071/RD08093)

Huang S, Sartini BL \& Parks JE 2008 Spermatogenesis in testis xenografts grafted from pre-pubertal Holstein bulls is re-established by stem cell or early spermatogonia. Animal Reproduction Science 103 1-12. (doi:10.1016/j.anireprosci.2006.11.018)

Jahnukainen K, Ehmcke J \& Schlatt S 2006 Testicular xenografts: a novel approach to study cytotoxic damage in juvenile primate testis. Cancer Research 66 3813-3818. (doi:10.1158/0008-5472.CAN-05-3754)

Jahnukainen K, Ehmcke J, Hergenrother SD \& Schlatt S 2007 Effect of cold storage and cryopreservation of immature non-human primate testicular tissue on spermatogonial stem cell potential in xenografts. Human Reproduction 22 1060-1067. (doi:10.1093/humrep/del471)

JAX 2000 Immunodeficient model selection: choosing a nude, scid or Rag1 strain. JAX ${ }^{\circledR}$ Communication ${ }^{\mathrm{TM}}$ 2. Available online in this site: http:// jaxmice.jax.org/jaxnotes/archive/480.pdf

Kaneko H, Kikuchi K, Nakai M \& Noguchi J 2008 Endocrine status and development of porcine testicular tissues in host mice. Journal of Reproduction and Development 54 480-485. (doi:10.1262/jrd.20081)

Kaneko H, Kikuchi K, Nakai M, Tanihara F, Noguchi J, Noguchi M, Ito J \& Kashiwazaki N 2012 Normal reproductive development of offspring derived by intracytoplasmic injection of porcine sperm grown in host mice. Theriogenology 78 898-906. (doi:10.1016/j.theriogenology.2012. 04.004)

Kaproth MT, Lee DR \& Parks JE 2002 Transplantation of testicular explants from prepubertal bulls to nude mice and ex situ production of haploid germ cells over 20-week period. In ASAS-ADSA Joint Annual Meeting, vol. 85, pp 302. Québec City, QC, Canada.

Kim Y, Selvaraj V, Dobrinski I, Lee H, McEntee MC \& Travis AJ 2006 Recipient preparation and mixed germ cell isolation for spermatogonial stem cell transplantation in domestic cats. Journal of Andrology 27 248-256. (doi:10.2164/jandrol.05034)

Kim Y, Selvaraj V, Pukazhenthi B \& Travis AJ 2007 Effect of donor age on success of spermatogenesis in feline testis xenografts. Reproduction, Fertility, and Development 19 869-876. (doi:10.1071/RD07056)

Luetjens MC, Stukenborg J-B, Nieschlag E, Simoni M \& Wistuba J 2008 Complete spermatogenesis in orthotopic but not in ectopic transplants of autologously grafted marmoset testicular tissue. Endocrinology 149 1736-1747. (doi:10.1210/en.2007-1325)

Mitchell RT, Childs AJ, Anderson RA, van den Driesche S, Saunders PT, McKinnell C, Wallace WH, Kelnar CJ \& Sharpe RM 2012 Do phthalates affect steroidogenesis by the human fetal testis? Exposure of human fetal testis xenografts to di- $n$-butyl phthalate. Journal of Clinical Endocrinology and Metabolism 97 E341-E348. (doi:10.1210/jc.2011-2411)

Mitchell RT, Sharpe RM, Anderson RA, McKinnell C, Macpherson S, Smith LB, Wallace WH, Kelnar CJ \& van den Driesche S 2013
Diethylstilboestrol exposure does not reduce testosterone production in human fetal testis xenografts. PLoS ONE 8 e61726. (doi:10.1371/journal. pone.0061726)

Mota PC, Ehmcke J, Westernströer B, Gassei K, Ramalho-Santos J \& Schlatt S 2012 Effects of different storage protocols on cat testis tissue potential for xenografting and recovery of spermatogenesis. Theriogenology 77 299-310. (doi:10.1016/j.theriogenology.2011.07. 042)

Nakai M, Kaneko H, Somfai T, Maedomari N, Ozawa M, Noguchi J, Kashiwazaki N \& Kikuchi K 2009 Generation of porcine diploid blastocysts after injection of spermatozoa grown in nude mice. Theriogenology 72 2-9. (doi:10.1016/j.theriogenology.2008.10.020)

Nakai M, Kaneko H, Somfai T, Maedomari N, Ozawa M, Noguchi J, Ito J, Kashiwazaki N \& Kikuchi K 2010 Production of viable piglets for the first time using sperm derived from ectopic testicular xenografts. Reproduction 139 331-335. (doi:10.1530/REP-09-0509)

Oatley JM, de Avila DM, Reeves JJ \& McLean DJ 2004 Spermatogenesis and germ cell transgene expression in xenografted bovine testicular tissue. Biology of Reproduction 71 494-501. (doi:10.1095/biolreprod.104. 027953)

Oatley JM, Reeves JJ \& McLean DJ 2005 Establishment of spermatogenesis in neonatal bovine testicular tissue following ectopic xenografting varies with donor age. Biology of Reproduction 72 358-364. (doi:10.1095/ biolreprod.104.030783)

Ohta H \& Wakayama T 2005 Generation of normal progeny by intracytoplasmic sperm injection following grafting of testicular tissue from cloned mice that died postnatally. Biology of Reproduction $\mathbf{7 3}$ 390-395. (doi:10.1095/biolreprod.105.041673)

Orwig KE \& Schlatt S 2005 Cryopreservation and transplantation of spermatogonia and testicular tissue for preservation of male fertility. Journal of the National Cancer Institute. Monographs 34 51-56. (doi:10.1093/jncimonographs/lgi029)

Pelleitier M \& Montplaisir S 1975 The nude mouse: a model of deficient T-cell function. Methods and Achievements in Experimental Pathology 7 149-166.

Plant TM, Gay VL, Marshall GR \& Arslan M 1989 Puberty in monkeys is triggered by chemical stimulation of the hypothalamus. PNAS $\mathbf{8 6}$ 2506-2510. (doi:10.1073/pnas.86.7.2506)

Poels J, Van Langendonckt A, Dehoux JP, Donnez J \& Wyns C 2012 Vitrification of non-human primate immature testicular tissue allows maintenance of proliferating spermatogonial cells after xenografting to recipient mice. Theriogenology 77 1008-1013. (doi:10.1016/ j.theriogenology.2011.10.015)

Povlsen CO, Skakkebaek NE, Rygaard J \& Jensen G 1974 Heterotransplantation of human foetal organs to the mouse mutant nude. Nature $\mathbf{2 4 8}$ 247-249. (doi:10.1038/248247a0)

Rathi R, Honaramooz A, Zeng W, Schlatt S \& Dobrinski I 2005 Germ cell fate and seminiferous tubule development in bovine testis xenografts. Reproduction 130 923-929. (doi:10.1530/rep.1.00912)

Rathi R, Honaramooz A, Zeng W, Turner R \& Dobrinski I 2006 Germ cell development in equine testis tissue xenografted into mice. Reproduction 131 1-9. (doi:10.1530/rep.1.01101)

Rathi R, Zeng W, Megee S, Conley A, Meyers S \& Dobrinski I 2008 Maturation of testicular tissue from infant monkeys after xenografting into mice. Endocrinology 149 5288-5296. (doi:10.1210/en.2008-0311)

Reddy N, Mahla RS, Thathi R, Suman SK, Jose J \& Goel S 2012 Gonadal status of male recipient mice influences germ cell development in immature buffalo testis tissue xenograft. Reproduction 143 59-69. (doi:10.1530/REP-11-0286)

Reed ND \& Manning DD 1978 Present status of xenotransplantation of nonmalignant tissue to the nude mouse. In The Nude Mouse in Experimental and Clinical Research, pp 167-185. Eds J Fogh \& BC Giovanella BC. New York: Academic Press.

Rodriguez-Sosa JR \& Dobrinski I 2009 Recent developments in testis tissue xenografting. Reproduction 138 187-194. (doi:10.1530/REP-09-0012)

Rodriguez-Sosa JR, Foster RA \& Hahnel A 2010 Development of strips of ovine testes after xenografting under the skin of mice and co-transplantation of exogenous spermatogonia with grafts. Reproduction 139 227-235. (doi:10.1530/REP-09-0176)

Rodriguez-Sosa JR, Rathi R, Wang Z \& Dobrinski I 2011 Development of bovine fetal testis tissue after ectopic xenografting in mice. Journal of Andrology 32 271-278. (doi:10.2164/jandrol.110.010322) 
Rodriguez-Sosa JR, Costa GM, Rathi R, França LR \& Dobrinski I 2012 Endocrine modulation of the recipient environment affects development of bovine testis tissue ectopically grafted in mice. Reproduction 144 37-51. (doi:10.1530/REP-12-0020)

Sato Y, Nozawa S, Yoshiike M, Arai M, Sasaki C \& Iwamoto T 2010 Xenografting of testicular tissue from an infant human donor results in accelerated testicular maturation. Human Reproduction 25 1113-1122. (doi:10.1093/humrep/deq001)

Sato T, Katagiri K, Gohbara A, Inoue K, Ogonuki N, Ogura A, Kubota Y \& Ogawa T 2011 In vitro production of functional sperm in cultured neonatal mouse testes. Nature 471 504-507. (doi:10.1038/nature09850)

Schlatt S, Kim SS \& Gosden R 2002 Spermatogenesis and steroidogenesis in mouse, hamster and monkey testicular tissue after cryopreservation and heterotopic grafting to castrated hosts. Reproduction 124 339-346. (doi:10.1530/rep.0.1240339)

Schlatt S, Honaramooz A, Ehmcke J, Goebell PJ, Rübben H, Dhir R, Dobrinski I \& Patrizio P 2006 Limited survival of adult human testicular tissue as ectopic xenograft. Human Reproduction 21 384-389. (doi:10. 1093/humrep/dei352)

Schlatt S, Westernströer B, Gassei K \& Ehmcke J 2010a Donor-host involvement in immature rat testis xenografting into nude mouse hosts. Biology of Reproduction 82 888-895. (doi:10.1095/biolreprod.109.082073)

Schlatt S, Gassei K, Westernstroer B \& Ehmcke J 2010b Modulating testicular mass in xenografting: a model to explore testis development and endocrine function. Endocrinology 151 4018-4023. (doi:10.1210/ en.2010-0415)

Schmidt JA, de Avila JM \& McLean DJ 2006 Effect of vascular endothelial growth factor and testis tissue culture on spermatogenesis in bovine ectopic testis tissue xenografts. Biology of Reproduction 75 167-175. (doi:10.1095/biolreprod.105.049817)

Schmidt JA, Avila JM \& McLean DJ 2007 Analysis of gene expression in bovine testis tissue prior to ectopic testis tissue xenografting and during the grafting period. Biology of Reproduction 76 1071-1080. (doi:10. 1095/biolreprod.106.058222)

Setchell BP 1990 The testis and tissue transplantation: historical aspects. Journal of Reproductive Immunology 18 1-8. (doi:10.1016/01650378(90)90020-7)

Shinohara T, Inoue K, Ogonuki N, Kanatsu-Shinohara M, Miki H, Nakata K, Kurome M, Nagashima H, Toyokuni S, Kogishi K et al. 2002 Birth of offspring following transplantation of cryopreserved immature pieces and in-vitro microinsemination. Human Reproduction 17 3039-3045. (doi:10.1093/humrep/17.12.3039)

Shirazi A, Khadivi A \& Shams-Esfandabadi N 2014 Male pronuclear formation using dog sperm derived from ectopic testicular xenografts, testis, and epididymis. Avicenna Journal of Medical Biotechnology 6 140-146.

Skakkebaek NE, Jensen G, Povlsen CO \& Rygaard J 1974 Heterotransplantation of human foetal testicular and ovarian tissue to the mouse mutant nude. Acta Obstetricia et Gynecologica Scandinavica 53 73-75. (doi:10.3109/00016347409157196)

Snedaker AK, Honaramooz A \& Dobrinski I 2004 A game of cat and mouse: xenografting of testis tissue from domestic kittens results in complete cat spermatogenesis in a mouse host. Journal of Andrology 25 926-930. (doi:10.1002/j.1939-4640.2004.tb03163.x)

Stukenborg J-B, Schlatt S, Simoni M, Yeung C-H, Elhija MA, Luetjens CM, Huleihel M \& Wistuba J 2009 New horizons for in vitro spermatogenesis? An update on novel three-dimensional culture systems as tools for meiotic and post-meiotic differentiation of testicular germ cells. Molecular Human Reproduction 15 521-529. (doi:10.1093/molehr/gap052)

Swerdloff RS, Walsh PC, Jacobs HS \& Odell WD 1971 Serum LH and $\mathrm{FSH}$ during sexual maturation in the male rat: effect of castration and cryptorchidism. Endocrinology 88 120-128. (doi:10.1210/endo-881-120)
Turner RM, Rathi R, Honaramooz A, Zeng W \& Dobrinski I 2010 Xenografting restores spermatogenesis to cryptorchid testicular tissue but does not rescue the phenotype of idiopathic testicular degeneration in the horse (Equus caballus). Reproduction, Fertility, and Development 22 673-683. (doi:10.1071/RD09014)

Valli H, Phillips BT, Shetty G, Byrne JA, Clark AT, Meistrich ML \& Orwig KE 2014 Germline stem cells: toward the regeneration of spermatogenesis. Fertility and Sterility 101 3-13. (doi:10.1016/j.fertnstert.2013.10.052)

Van Saen D, Goossens E, Bourgain C, Ferster A \& Tournaye H 2011 Meiotic activity in orthotopic xenografts derived from human postpubertal testicular tissue. Human Reproduction 26 282-293. (doi:10.1093/ humrep/deq321)

Van Saen D, Goossens E, Haentjens P, Baert Y \& Tournaye H 2013 Exogenous administration of recombinant human $\mathrm{FSH}$ does not improve germ cell survival in human prepubertal xenografts. Reproductive Biomedicine Online 26 286-298. (doi:10.1016/j.rbmo.2012.11.013)

Wistuba J, Mundry M, Luetjens CM \& Schlatt S 2004 Cografting of hamster (Phodopus sungorus) and marmoset (Callithrix jacchus) testicular tissues into nude mice does not overcome blockade of early spermatogenic differentiation in primate grafts. Biology of Reproduction 71 2087-2091. (doi:10.1095/biolreprod.104.033431)

Wistuba J, Luetjens CM, Wesselmann R, Nieschlag E, Simoni M \& Schlatt S 2006 Meiosis in autologous ectopic transplants of immature testicular tissue grafted to Callithrix jacchus. Biology of Reproduction 74 706-713. (doi:10.1095/biolreprod.105.048793)

Wyns C, Van Langendonckt A, Wese F-X, Donnez J \& Curaba M 2008 Long-term spermatogonial survival in cryopreserved and xenografted immature human testicular tissue. Human Reproduction 23 2402-2414. (doi:10.1093/humrep/den272)

Wyns C, Curaba M, Vanabelle B, Van Langendonckt A \& Donnez J 2010 Options for fertility preservation in prepubertal boys. Human Reproduction Update 16 312-328. (doi:10.1093/humupd/dmp054)

Yu J, Cai Z-M, Wan H-J, Zhang F-T, Ye J, Fang J-Z, Gui Y-T \& Ye J-X 2006 Development of neonatal mouse and fetal human testicular tissue as ectopic grafts in immunodeficient mice. Asian Journal of Andrology 8 393-403. (doi:10.1111/j.1745-7262.2006.00189.x)

Zeng W, Avelar GF, Rathi R, Franca LR \& Dobrinski I 2006 The length of the spermatogenic cycle is conserved in porcine and ovine testis xenografts. Journal of Andrology 27 527-533. (doi:10.2164/jandrol.05143)

Zeng W, Rathi R, Pan H \& Dobrinski I 2007 Comparison of global gene expression between porcine testis tissue xenografts and porcine testis in situ. Molecular Reproduction and Development 74 674-679. (doi:10.1002/mrd.20670)

Zeng W, Snedaker AK, Megee S, Rathi R, Chen F, Honaramooz A \& Dobrinski I 2009 Preservation and transplantation of porcine testis tissue. Reproduction, Fertility, and Development 21 489-497. (doi:10.1071/ RD08235)

Zeng W, Baumann C, Schmidtmann A, Honaramooz A, Tang L, Bondareva A, Dores C, Fan T, Xi S, Geiman T et al. 2011 Lymphoidspecific helicase (HELLS) is essential for meiotic progression in mouse spermatocytes. Biology of Reproduction 84 1235-1241. (doi:10.1095/ biolreprod.110.085720)

Received 12 May 2014

First decision 11 June 2014

Revised manuscript received 31 July 2014

Accepted 21 August 2014 